\title{
The thermodynamic predictability of sea ice ${ }^{*}$
}

\author{
ROBERT W. GRUMBINE \\ National Meteorological Center, Camp Springs, Maryland 20746, U.S.A.
}

\begin{abstract}
Statistical analyses and model experiments suggest that the sea-ice cover is predictable weeks to months in advance. As such, it is one of the most highly predictable components of the climate system. The thermodynamic mechanisms by which this predictability can be realized are examined. It is found that the predictability is dependent on the differential growth/decay of sea ice as a function of thickness. In winter or year-round, for thin ice, the growth/decay rates are a strong function of thickness, which gives a relatively short period of predictability, though still long compared to the atmosphere. In summer, or year-round for thick ice, growth/decay rates are only weak functions of thickness and the period of predictability is comparatively long.
\end{abstract}

\section{PHYSICAL PARAMETERS AND THEIR VALUES}

$\begin{array}{ll}f & \mathrm{~ms}^{-1} \\ g & \mathrm{~m}^{-1}\end{array}$

$$
\begin{array}{ll}
\rho_{\mathrm{a}} & 1.2 \mathrm{~kg} \mathrm{~m}^{-3} \\
U_{\mathrm{a}} & 5 \mathrm{~m} \mathrm{~s}^{-1} \\
C_{\mathrm{h}} & 1.75 \times 10^{-3} \\
& \\
C_{\mathrm{p}} & 1004 \mathrm{~J} \mathrm{~kg}^{-1} \mathrm{~K}^{-1} \\
T_{\mathrm{g}} & \mathrm{K}
\end{array}
$$$$
T_{\mathrm{a}}
$$$$
243 \mathrm{~K}
$$$$
278 \mathrm{~K}
$$$$
T_{\mathrm{f}} \quad 271.3 \mathrm{~K}
$$$$
C_{\mathrm{q}} \quad 1.75 \times 10^{-3}
$$$$
L_{\mathrm{v}} \quad 2.834 \times 10^{6} \mathrm{~J} \mathrm{~kg}^{-1}
$$$$
k_{8} \quad 0.31 \mathrm{~W} \mathrm{~m}^{-1} \mathrm{~K}^{-1}
$$$$
k_{\mathrm{i}} \quad 2.2 \mathrm{~W} \mathrm{~m}^{-1} \mathrm{~K}^{-1}
$$$$
H_{\mathrm{s}} \quad \mathrm{m}
$$$$
H_{\mathrm{i}} \quad \mathrm{m}
$$$$
\text { C }
$$

$\begin{array}{ll}\epsilon_{\mathrm{i}} & 0.97\end{array}$
Ice growth/melt rate

Fraction of area centered at location $x, y$ at time $t$ which is covered by ice of thickness $h$ to $h+\mathrm{d} h$

Air density

Air speed

Sensible-heat transfer coefficient (Maykut, 1978)

Specific heat of air

Surface temperature of ice/ snow

Air temperature

Winter

Summer

Freezing point of sea water

Latent-heat transfer coefficient

Latent heat of vaporization of ice

Thermal conductivity of snow

Thermal conductivity of ice

Snow thickness

Ice thickness

Cloudiness

Winter (Parkinson and Washington, 1979)

Summer (Parkinson and

Washington, 1979)

Longwave emissivity of ice (Parkinson and Washington, 1979)

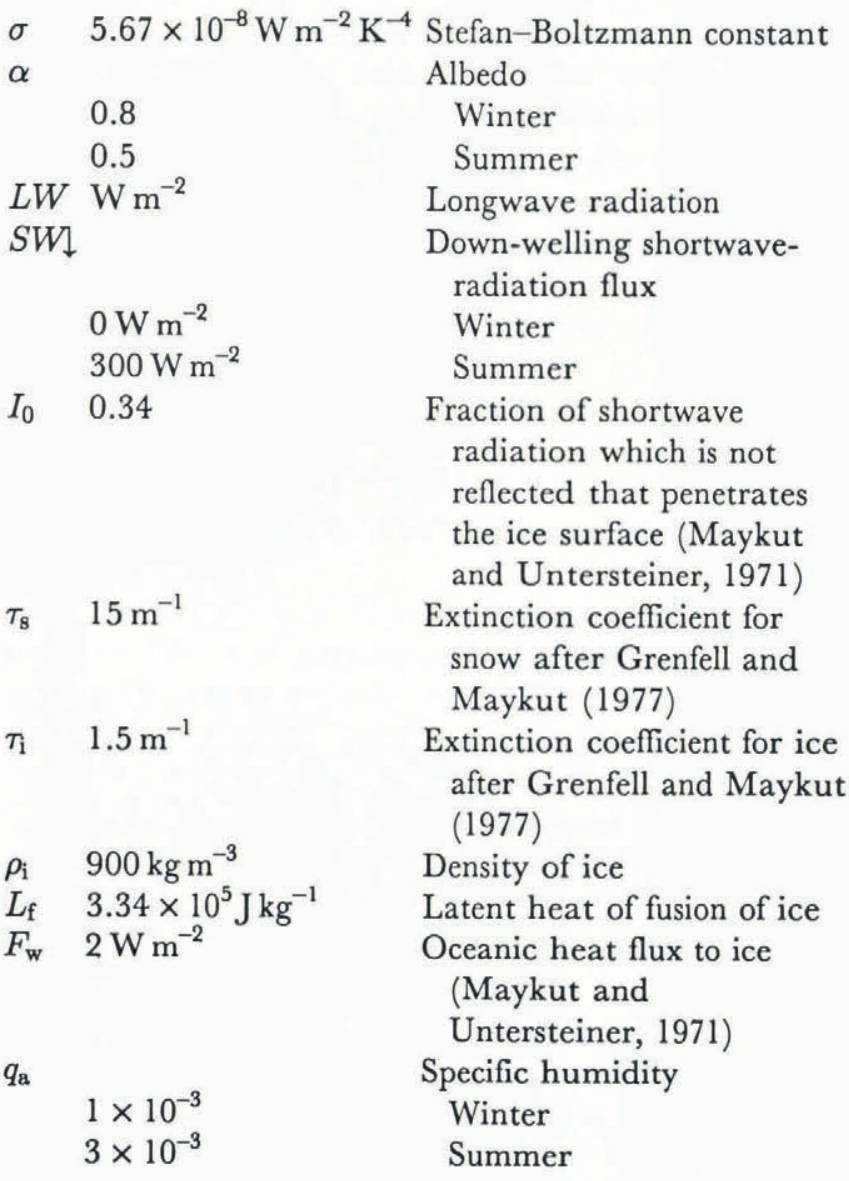

\section{INTRODUGTION}

Statistical analyses of sea-ice prediction (ice-edge location and area concentration) suggest that sea ice is predictable weeks and months in advance, given present anomaly fields (deviations from climatology) for one or more of the atmosphere, cryosphere and hydrosphere (Walsh and Johnson, 1979; Walsh, 1980; Chapman and Walsh, 1991; Marsden and others, 1991). Specific anomaly fields considered have included ice extent, surface salinity,

\footnotetext{
* Ocean Products Center contribution No. 64.
} 
$50 \mathrm{~m}$ temperature, 400-600 $\mathrm{m}$ salinity (Marsden and others, 1991), ice area, sea-surface temperature, 700 mbar pressure field and surface-air temperature (Chapman and Walsh, 1991), surface temperature and sea-level pressure (Walsh, 1980), surface temperature, sea-level pressure, 700 mbar heights and temperatures (Walsh and Johnson, 1979). The apparent successes of the statistical analyses suggest that model-based ice forecasting might be successful on similar time-scales. Determining how far into the future such a forecast might be skillful (more accurate than climatology) is one purpose here.

An ice-model experiment (Hibler and Walsh, 1982) finds a significant correlation, 0.48 , for a thermodynamics-only prediction of the Arctic ice-edge location. Adding dynamics increases the correlation to 0.58 , which suggests that the dynamics are helpful but that much of the predictive skill lies with the thermodynamics.

An ice-thermodynamics model is taken to examine reasons for the predictability of sea ice. Specific features to be understood are: why is the present ice anomaly a better predictor (providing a more accurate forecast than climatology for a longer period, i.e. more skillful) than atmospheric anomalies (Walsh and Johnson, 1979; Walsh, 1980; Johnson and others, 1985); why is the time-scale of prediction weeks rather than days as it is for the atmosphere; and why is the time-scale of predictability longer in the spring and summer melt season than in the fall and winter freezing season. Since an incomplete physical model is taken here, rigorous answers to these questions are not possible. It is suggested, though, that if characteristics are found while examining the thermodynamic processes alone which are similar to the characteristics observed in Nature, then Nature is governed by thermodynamics in those situations.

\section{ICE-THICKNESS DISTRIBUTION}

An icepack is composed of many thicknesses of ice. We prefer to treat the icepack as a continuum, which means that we view the ice at a scale which is large compared to the size of individual floes. Consequently, each region of the continuum also contains floes of many different thicknesses. Certain thermodynamic processes, such as the conduction of heat through the ice, are sensitive to ice thickness. So, we need to track the fraction of the area of any region which is covered by ice of a given thickness. This gives rise to the notion of an ice-thickness distribution (Thorndike and others, 1975) $g(x, y, t ; h)$. The fraction of area centered at location $x, y$ at time $t$ which is covered by ice between thickness $h$ and $h+\mathrm{d} h$ is given by $g$. The ice-thickness distribution will change due to thermodynamic effects (freezing and melting) and dynamical effects (ridging, rafting and crushing). Only the thermodynamic part of the evolution equation for the ice-thickness distribution will be used as the basis for analysis in this study.

The thermodynamics-only ice-thickness distribution evolution is given by

$$
\frac{\partial g}{\partial t}+\frac{\partial f g}{\partial h}=0
$$

after Thorndike and others (1975) but neglecting lateral ice freezing. $f$ is the rate of freeze or melt, in $\mathrm{m} \mathrm{s}^{-1}$, of ice with thickness $h$.

Consider the meaning of climatology in this context. Climate refers to some typical annual cycles in both $g$ and $f$, which will be denoted by $\bar{g}$ and $\bar{f}$. Also, the definition is required that:

$$
\frac{\partial \bar{g}}{\partial t}+\frac{\partial \bar{f} \bar{g}}{\partial h}=0
$$

which includes the approximation that the mean of the products is equal to the product of the means.

Anomalies in ice extent or coverage will appear as anomalies in $g$. Thus, $g=\bar{g}+g^{\prime}$, where $g^{\prime}$ are the anomalies. Atmospheric or oceanic anomalies, such as a warm summer or cold winter, will contribute to $f^{\prime}$. Note that the anomalies from the atmosphere and ocean are only important to this model in so far as they affect the freezing or melting rate of the ice. The freezing rate and ice-thickness perturbations are not necessarily small. Near the ice edge, they are always large (the climatic term is near-zero). In order to examine the physical processes which are most important, Equation (1) will be linearized.

Here, $\bar{f}$ is considered known and is uncoupled from the ice-thickness distribution $g$. So we lack non-linear feed-back, the element which usually limits predictability. Consider instead the ice-thickness distribution perturbation, $g^{\prime}$. If $g^{\prime}$ is smaller than our ability to distinguish it from zero, and hence our ability to distinguish $g$ from $\bar{g}$, then predictability is lost. In this case, climatology is equally as good as the model at forecasting the distribution at this future time. Conversely, consider an initial state which contains an unmeasurably small error. If that perturbation grows large enough to be measurable, predictive skill is lost.

Now let us examine the perturbation equation derived by substituting $g=\bar{g}+g^{\prime}$ and $f=\bar{f}+f^{\prime}$ into Equation (1), suggestively rewritten, including both processes:

$$
\begin{aligned}
\frac{\partial g^{\prime}}{\partial t}+ & {\left[\left(\bar{f}+f^{\prime}\right) \frac{\partial g^{\prime}}{\partial h}+f^{\prime} \frac{\partial \bar{g}}{\partial h}\right] } \\
& +\left[g^{\prime} \frac{\partial\left(\bar{f}+f^{\prime}\right)}{\partial h}+\bar{g} \frac{\partial f^{\prime}}{\partial h}\right]=0
\end{aligned}
$$

where the identity from Equation (2) has already been applied. The first bracketed term represents a onedimensional wave equation for the thickness distribution propagating through time and thickness. The first half gives the propagation speed of thickness anomalies, while the second describes the perturbations due to a perturbed propagation rate of the climatological thickness distribution. The wave-like nature of this term was discussed by Coon and others (1974). The second bracketed term describes an anomaly dissipation or growth term. The first part amplifies (since $\partial f / \partial h$ is normally non-positive) the perturbation $g^{\prime}$. The second part of the term contributes anomalies due to anomalous dispersion of the climatological thickness distribution.

The wave-like term suggests high predictability. Given $f^{\prime}$ and $\bar{f}, g$ can be computed indefinitely into the future without $g^{\prime}$ decaying or growing. The purely propagating term has no means of amplifying or 
shrinking the perturbations. For example, consider the thickness at which $g^{\prime}$ is largest. At that thickness $\partial g^{\prime} / \partial h$ is zero. So the advection is also zero and the wave term cannot change $g^{\prime}$ at that location.

The second terms provide means for predictive skill to be lost. The second term within brackets provides a mechanism for $g^{\prime}$ to grow through the production of thickness anomalies due to anomalous dispersion of the climatological thickness distribution. The first term within the second bracket provides a means of error growth through amplification of the perturbation in $g^{\prime}$. This perturbation means that there is excess or deficit area being covered by ice between two thicknesses. The thinner ice grows more rapidly than the thicker ice so, after some time, the same area of perturbation is confined into a narrower band of thicknesses. $g^{\prime}$ must therefore be larger, because its integral over thickness must equal the same area for the perturbation as before the perturbed ice was allowed to grow. The argument applies to melting as well, with the thicker ice melting more rapidly. The e-folding time for perturbation growth by this means is $|(\partial f / \partial h)|^{-1}$, which varies from hours to years depending on the thickness and the season. The concentration of the perturbation into an ever-smaller range of thicknesses can be thought of as a negative dispersion.

\section{PREDICTABILITY}

Now we can begin to address the question of why the iceedge location is more accurately forecast or accurately forecast further into the future when using ice-anomaly fields rather than atmospheric anomaly fields. Consider a (finite) perturbation to the ice-thickness distribution in the presence of a climatological atmosphere $\left(f^{\prime} \equiv 0\right)$. The evolution of the perturbation will be

$$
\frac{\partial g^{\prime}}{\partial t}+\bar{f} \frac{\partial g^{\prime}}{\partial h}+g^{\prime} \frac{\partial \bar{f}}{\partial h}=0
$$

During the freezing season, $\bar{f}$ is positive and decreases monotonically with $h$. So $\partial \bar{f} / \partial h$ is strictly negative and will amplify perturbations. For illustrative purposes, the ice-growth/decay model discussed in the next section has been used to derive freezing and melting rates for winter and summer conditions, respectively. The freezing and melting rates so derived are illustrated in Figure 1. The assumed winter and summer conditions have been given above. For $\bar{f}$ proportional to $\alpha h^{-\beta}$, the approximate form of $\bar{f}$ found by curve-fitting the winter freezing rates illustrated in Figure 1, the e-folding period is $h^{1+\beta} /(\alpha \beta)$. Typical values are $\alpha=1.37$ and $\beta=0.82$, where time is in days and thickness is in centimeters. Note that the length of predictive skill increases rapidly for increasingly thick ice. Under a climatological atmosphere, the icethickness distribution-adjustment time-scale is about $20 \mathrm{~h}$ for $10 \mathrm{~cm}$ thick ice, $64 \mathrm{~h}$ for $20 \mathrm{~cm}$ ice, $20 \mathrm{~d}$ for $60 \mathrm{~cm}$ thickness and 1.3 years for $3 \mathrm{~m}$ thick ice. The latter thicknesses correspond to mean thicknesses of the Antarctic (Wadhams and others, 1987) and the Arctic (Bourke and Garrett, 1987), respectively.

Now, consider the early (i.e. linearizeable) growth of perturbations to the sea-ice thickness distribution due to

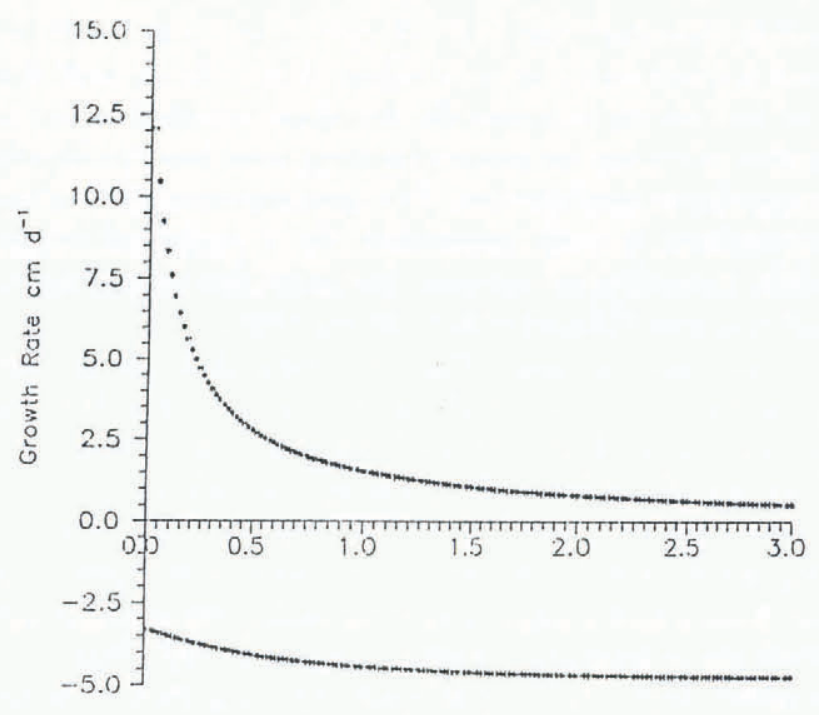

Ice Thickriess (m)

Fig. 1. Freezing rate in $\mathrm{cm} \mathrm{d}^{-1}$ as a function of thickness in meters for winter (upper curve) and summer (lower curve).

freezing-rate anomalies

$$
\frac{\partial g^{\prime}}{\partial t}+\frac{\partial g^{\prime} \bar{f}}{\partial h}=-\frac{\partial f^{\prime} \bar{g}}{\partial h} .
$$

The growth of the ice-thickness anomalies, $g^{\prime}$, is accomplished through either negative dispersion of the perturbation with respect to thickness (the second term in Equation (5)), or by anomalous propagation and dispersion of the climatological thickness distribution (the third term). The equilibrium response in $g^{\prime}$ to an anomaly in freezing is $g^{\prime}=\left(-f^{\prime} / \bar{f}\right) \bar{g}+C$ where $C$ is a constant of integration which is taken as zero to satisfy area conservation. For sufficiently small $f^{\prime}, g^{\prime}$ is never large. For $\bar{g}$ small, $g^{\prime}$ is also constrained to be small. The only time or place that $g^{\prime}$ may be large is when $f^{\prime}$ is large and $\bar{f}$ is small, namely where the deviation from climatological freezing rates is large and the climatological freezing rate itself is small. This places us in the marginal ice zone during a time of anomalously cold weather. In the interior icepack, then freezing-rate anomalies are usually unable to produce large anomalies in ice-thickness distribution ( $g$ is large but $f^{\prime}$ is thicknessdependent, decreasing with thickness and the thickness is large).

Now, consider the relative roles of $f^{\prime}$ and $\bar{f} . f^{\prime}$ acts to introduce anomalies into the ice-thickness distribution by perturbing the climatological cycle of ice growth and decay. Once an ice-thickness anomaly is produced, the climatological freezing rates propagate the change through thickness at a rate $f$ and concentrate it into an increasingly narrow thickness range at a rate proportional to $|(\partial \bar{f} / \partial h)|^{-1}$. This allows us to answer the question of why a present ice-anomaly field is a more skillful ice predictor than the atmospheric anomaly is. The amplification of an anomaly in the ice distribution occurs on a time-scale of $|(\partial \bar{f} / \partial h)|^{-1}$. The production of an icethickness distribution anomaly, on the other hand, occurs on the time-scale of $\left|\left(\partial f^{\prime} / \partial h\right)\right|^{-1}$, which will generally exceed the amplification period. If we already know that the thickness distribution is perturbed (again, thick ice 
will be most important), this distribution can be predicted well into the future as we now start with $g^{\prime}$ being zero and can successfully compute the thickness distribution out to a time when the anomalous freezing rates have produced a significant perturbation. The instantaneous state of the atmosphere is only predictable for a couple of weeks, while anomalies in ice-cover concentration ice persist for up to a year (Marsden and others, 1991).

We also see from Figure 1 why there is greater predictability in the melt season than in the freezing season. Figure 1 presents melting and freezing rates as a function of thickness for summer and winter; physical parameters are given in section 1 . The melt rate is far less dependent on thickness than the freezing rate. Except for ice thinner than, say, $50 \mathrm{~cm}$, the freezing rate is essentially thickness-independent. Figure 2 presents $|(\partial f / \partial h)|^{-1}$ for summer and winter conditions, showing that it is far larger in summer than winter. For summer melt rates, the predictive scale for $60 \mathrm{~cm}$ ice is 2.2 years, and 361 years for $3 \mathrm{~m}$ thick ice, as opposed to $20 \mathrm{~d}$ and 1.3 years for freezing, respectively. The summer predictive time-scale is far longer than the time required to melt all the ice (or for summer to end). So, the thermodynamics do not limit predictive skill in the summer or for the thickest ice in winter.

Ocean anomalies, such as an anomalously low-salinity or warm upper layer, affect predictability only indirectly. The contribution of the ocean to the ice-heat balance, and hence freezing/melting rates, is thickness-dependent. So, the ocean makes no contribution to the dispersion term. The ocean can affect predictability by acting to produce thicker or thinner ice. As already seen, thinner ice is less predictable. So, if the ocean were warmer, giving rise to a thinner ice cover, the predictability period for the ice would be decreased. The quantity of interest here is the heat flux from the ocean to the ice.

From our analysis of anomaly preservation, a predictive time-scale of several weeks (Walsh and Johnson, 1979; Walsh, 1980; Chapman and Walsh, 1991; Marsden and others, 1991) suggests that the most important ice is thick, over, say, $50 \mathrm{~cm}$ (2 week winter

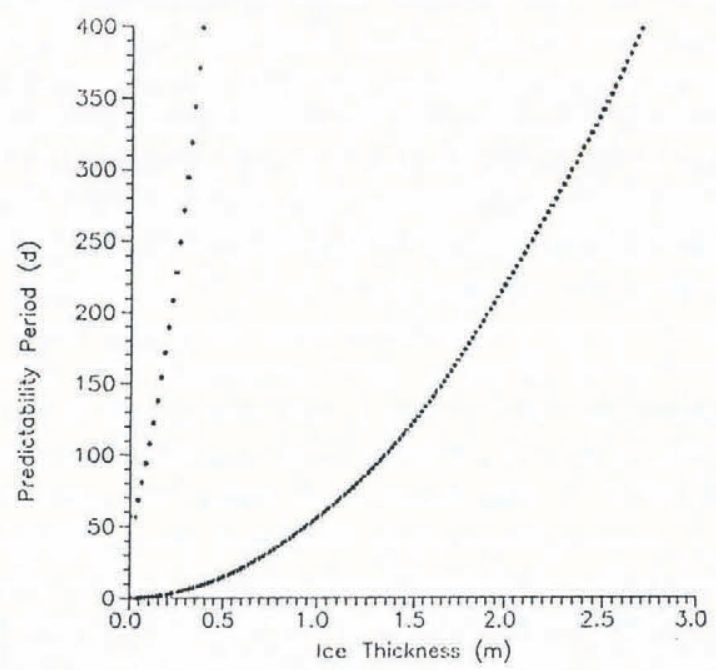

Fig. 2. e-folding period in days of errors in the icethickness distribution as a function of ice thickness in meters. Upper curve is for summer conditions, lower curve is for winter conditions. predictability). Both Arctic and Antarctic icepacks have a wintertime mean thickness greater than this, which corroborates our expectation.

\section{FREEZING-RATE SENSITIVITY TO THE ATMOSPHERE AND OGEAN}

A closer examination of the ice thermodynamics is now in order. Figure 3 illustrates the thermodynamic terms involved in ice-floe freezing and melting. The formulation of the thermodynamics follows the zero-level version of Semtner's (1976) solution, except that penetrating shortwave radiation is used to melt the ice as a whole rather than in forming an internal energy store.

$H \downarrow L E \downarrow \quad \epsilon_{i} L W \downarrow \quad \epsilon_{i} \sigma T_{S}^{4} \uparrow(1-\alpha)\left(1-I_{0}\right) S W \downarrow$
Conduction $\uparrow \quad \beta_{s} I_{0}(1-\alpha) S W \downarrow$
SNOW
Conduction $\uparrow \quad\left(1-\beta_{s}\right) \beta_{i} I_{0}(1-\alpha) S W \downarrow$
$\quad \operatorname{ICE} E$
$F W \uparrow\left(1-\left(\left(1-\beta_{s}\right) \beta_{i}\right)\right) I_{0}(1-\alpha) S W \downarrow$

Fig. 3. Diagram of ice-thermodynamic variables. $H$ is the sensible-heat flux, $L E$ is the latent-heat flux, $L W$ is the longwave-energy flux away from the ice, $\epsilon_{\mathrm{i}} \sigma T_{\mathrm{s}}^{4}$ is the longwave-energy flux away from the ice, $S W$ is the downwelling shortwave energy, $\alpha$ is the albedo, $I_{0}$ is the fraction of the shortwave energy which penetrates the surface, $\beta_{8}$ is the fraction of down-welling shortwave energy which is absorbed in the snow layer (if any), $\beta_{\mathrm{i}}$ is the fraction of down-welling shortwave energy which is absorbed in the ice and $F W$ is the heat flux from the ocean to the ice. Energy fluxes are measured negative towards the ice.

In the winter (freezing conditions), the ice-surface fluxes are forced to sum to zero by adjusting the surface temperature to provide flux balance. The contributing fluxes are: sensible-heat flux $(H)$, latent-heat flux $(L E)$, conductive-heat flux $(K)$, down-welling longwave-radiation flux $(L W \downarrow)$, up-welling longwave-radiation flux $(L W \uparrow)$ and absorbed shortwave-radiation flux ( $\left.S W_{\text {net }}\right)$. We formulate the fluxes as:

$$
\begin{gathered}
H=\rho_{\mathrm{a}} U_{\mathrm{a}} C_{\mathrm{h}} C_{\mathrm{p}}\left(T_{\mathrm{s}}-T_{\mathrm{a}}\right) \\
L E=\rho_{\mathrm{a}} U_{\mathrm{a}} C_{\mathrm{q}} L_{\mathrm{v}}\left(q_{\mathrm{s}}\left(T_{\mathrm{s}}\right)-q_{10}\left(T_{\mathrm{a}}\right)\right) \\
K=-k_{\mathrm{s}} k_{\mathrm{i}}\left(T_{\mathrm{f}}-T_{\mathrm{s}}\right) /\left(k_{\mathrm{s}} H_{\mathrm{i}}+k_{\mathrm{i}} H_{\mathrm{s}}\right) \\
L W \downarrow=-\left(0.7855+0.2232 C^{2.75}\right) \epsilon_{\mathrm{i}} \sigma T_{\mathrm{a}}^{4} \\
L W \uparrow=\epsilon_{\mathrm{i}} \sigma T_{\mathrm{s}}^{4} \\
S W_{\text {net }}=-(1-\alpha) S W \downarrow \\
\quad \cdot\left(1-I_{0} \exp \left(-\left(H_{\mathrm{s}} \tau_{\mathrm{s}}+H_{\mathrm{i}} \tau_{\mathrm{i}}\right)\right)\right)
\end{gathered}
$$


where $k_{\mathrm{B}}$ and $k_{\mathrm{i}}$ are the thermal conductivities of snow and ice, respectively, $H_{8}$ and $H_{\mathrm{i}}$ are the thicknesses of snow and ice, respectively, $T_{\mathrm{f}}$ is the freezing temperature of sea water, $T_{\mathrm{B}}$ is the surface temperature of the floe, $C_{\mathrm{h}}$ is the bulk-transfer coefficient for sensible heat, $C_{\mathrm{q}}$ is the bulk-transfer coefficient for latent heat, $U_{\mathrm{a}}$ is the atmospheric wind speed at $10 \mathrm{~m}, C_{\mathrm{p}}$ is the specific heat of air, $L_{\mathrm{v}}$ is the latent heat of vaporization of ice, $q_{\mathrm{s}}$ is the saturation water-vapor content at temperature $T_{\mathrm{s}}, q_{10}$ is the actual water-vapor content at $10 \mathrm{~m}, \epsilon$ is the longwave emissivity of the surface (snow or ice), $C$ is the cloud-cover fraction, $\alpha$ is the surface albedo, $S W \downarrow$ is the down-welling shortwave-radiation flux, $I_{0}$ is the fraction of incident solar radiation which penetrates the surface and $\tau_{\mathrm{s}}$ and $\tau_{\mathrm{i}}$ are the shortwave-extinction coefficients for snow and ice, respectively. The longwave down-welling flux relation is the empirical relation due to Maykut and Church (1973). The convention that fluxes are positive away from the ice is assumed.

The freezing rate $\left(\mathrm{m} \mathrm{s}^{-1}\right.$ of ice thickening) has been given by Semtner (1976):

$$
\begin{gathered}
f=\frac{\partial H_{\mathrm{i}}}{\partial t}=\left(-F_{\mathrm{w}}+k_{\mathrm{s}} k_{\mathrm{i}}\left(T_{\mathrm{f}}-T_{\mathrm{s}}\right) /\left(k_{\mathrm{s}} H_{\mathrm{i}}+k_{\mathrm{i}} H_{\mathrm{s}}\right)\right) \\
/\left(\rho_{\mathrm{i}} L_{\mathrm{f}}\right)
\end{gathered}
$$

where $F_{\mathrm{w}}$ is the oceanic heat flux into the ice. Note that this may produce basal melting when the conduction is slow, either because of thick snow and ice or because of warm surfaces. In summer, $T_{\mathrm{s}}$ is limited to the freezing point of the ice and excess flux into the ice results. This flux is balanced by increased melting:

$$
f=\frac{\partial H_{\mathrm{i}}}{\partial t}=\left(-F_{\mathrm{w}}+Q_{\text {extra }}\right) /\left(\rho_{\mathrm{i}} L_{\mathrm{f}}\right)
$$

where $Q_{\text {extra }}$ is the sum of the surface-flux terms at $T_{\mathrm{s}}=T_{\mathrm{f}}$. The thermodynamic picture used here is not strictly accurate in the freezing season for ice thinner than about $50 \mathrm{~cm}$ or in the summer-melt season. Under these conditions, certain mechanical processes (rafting of small floes and formation of brine channels and subsequent mechanical break-up) have potentially significant effects on the ice physics (Maykut, 1986). Nonetheless, the larger-scale considerations of thermodynamics do apply, in that even though brine channeling may permit melt without changing the thickness of the ice, the volume of ice melted still corresponds to that which would be expected thermodynamically. Values of the constants have already been given.

Equations (12) and (13) give the freezing or melting rate $(f)$ after $T_{\mathrm{s}}$ has been determined from Equations (6)-(11). Our main interest in terms of sea-ice predictability is $|(\partial f / \partial h)|^{-1}$. For winter, after differentiating Equation (12) with respect to $H_{\mathrm{i}}$, and recalling that the surface temperature can depend on ice thickness, we find

$$
\begin{aligned}
\left(\frac{\partial f}{\partial h}\right)^{-1}= & -\frac{\rho_{\mathrm{i}} L_{\mathrm{f}}\left(k_{\mathrm{s}} H_{\mathrm{i}}+k_{\mathrm{i}} H_{\mathrm{s}}\right)}{k_{\mathrm{s}} k_{\mathrm{i}}} \\
& \cdot\left[\frac{\left(T_{\mathrm{f}}-T_{\mathrm{s}}\right) k_{\mathrm{s}}}{k_{\mathrm{s}} H_{\mathrm{i}}+k_{\mathrm{i}} H_{\mathrm{s}}}+\frac{\partial T_{\mathrm{s}}}{\partial H_{\mathrm{i}}}\right]^{-1}
\end{aligned}
$$

where

$$
\begin{aligned}
& \frac{\partial T_{\mathrm{s}}}{\partial H_{\mathrm{i}}}= \\
& \frac{\left.\left[\frac{\left(T_{\mathrm{f}}-T_{\mathrm{s}}\right) k_{\mathrm{s}}^{2} k_{\mathrm{i}}}{\left(k_{\mathrm{s}} H_{\mathrm{i}}+k_{\mathrm{i}} H_{\mathrm{s}}\right)^{2}}-(1-\alpha) S W \downarrow I_{0} \tau_{\mathrm{i}} \exp \left(-H_{\mathrm{s}} \tau_{\mathrm{s}}+H_{\mathrm{i}} \tau_{\mathrm{i}}\right)\right)\right]}{\frac{-k_{\mathrm{s}} k_{\mathrm{i}}}{\left(k_{\mathrm{s}} H_{\mathrm{i}}+k_{\mathrm{i}} H_{\mathrm{s}}\right)}+\rho_{\mathrm{a}} C_{\mathrm{q}} L_{\mathrm{v}} U_{\mathrm{a}} \frac{\partial q_{\mathrm{s}}}{\partial T_{\mathrm{s}}} \rho_{\mathrm{a}} C_{\mathrm{D}} C_{\mathrm{p}} U_{\mathrm{a}}+4 \epsilon O T_{\mathrm{s}}^{3}} .
\end{aligned}
$$

The salient feature of Equation (15) is that the ice surface cools for thicker ice. Therefore, the ice-freezing rate is less dependent on thickness than if $T_{\mathbf{s}}$ were thickness-independent. This gives a longer period of predictability. In the summer, $T_{\mathrm{B}}$ is fixed by the freezing point, so the $\partial f / \partial h$ is given by

$$
\left(\frac{\partial f}{\partial h}\right)^{-1}=\rho_{\mathrm{i}} L_{\mathrm{f}}\left(\frac{\partial Q_{\text {extra }}}{\partial h}\right)^{-1}
$$

where

$$
\frac{\partial Q_{\text {extra }}}{\partial h}=-(1-\alpha) S W \downarrow I_{0} \tau_{\mathrm{i}} \exp \left(-\left(h_{\mathrm{s}} \tau_{\mathrm{s}}+h_{\mathrm{i}} \tau_{\mathrm{i}}\right)\right),
$$

so we see that in summer the only dependence of melt rate on ice/snow thickness comes about from the additional shortwave radiation absorbed by thicker ice. Since $\partial Q / \partial h$ is an exponential function of thickness, it is only for thin ice that the melt rate becomes sensitive to thickness. Hence, the summer ice has an extremely long predictability period. Returning to Figure 2 shows that the period estimated for predictability is longer than the period required to melt the entire floe under the presumed conditions.

\section{DISCUSSION}

This analysis suggests answers to some questions which are important to understanding and forecasting sea-ice conditions. First, it is apparent from earlier work that the time-scale of sea-ice anomaly persistence is weeks to months (Walsh and Johnson, 1979; Walsh 1980; Chapman and Walsh, 1991; Marsden and others, 1991). We see here that this is expected for regions of thick ice, as this ice can respond only slowly to atmospheric anomalies. The length of ice-anomaly persistence is longer in the melt season than in the freezing season because the freezing process is more thickness-dependent than melting (larger $\mathrm{d} f / \mathrm{d} h$ ). The relative ease with which ice anomalies (once formed) are predicted suggests that statistical forecasting models such as autoregressive models of ice anomalies are liable to be more accurate than climatology for longer lead times than a regression of the ice anomaly based on past atmospheric anomalies, in accord with experience (Walsh and Johnson, 1979; Walsh, 1980; Johnson and others, 1985).

Another feature of operational interest is that, given knowledge of the atmosphere, we can also estimate the period for which an ice-thickness forecast may be expected to be better than climatology due to thermodynamics. The estimates are high, years in the summer versus weeks inferred by studies (cf. Walsh and Johnson, 1979; Walsh, 1980; Chapman and Walsh, 1991; Marsden and others, 1991). The likely candidate for the discrep- 
ancy is the absence of dynamics in this analysis. For a large-scale icepack, convergence is of the order of $10^{-2} \mathrm{~d}^{-1}$ (Coon and others, 1974), which corresponds to a $100 \mathrm{~d}$ predictability limit. This limit is reached by ice thicknesses of $10 \mathrm{~cm}$ in the summer and $1.36 \mathrm{~m}$ in the winter. So, it is suggested that these are the conditions which contribute to the observed characteristics of sea-ice predictability.

Ice dynamics are definitely an important element in ice prediction. In the long term and large scale, dynamics limit the prediction range. At small scales and short range, when divergence can be much larger, dynamics again limit the prediction range. Further, via ridging, dynamics will affect the ice-thickness distributionremoving ice from thin classes and pushing it into thick classes.

The thermodynamic limit on predictability will be an important consideration for predicting thin ice in the melt season, or with new, young or first-year ice in the winter. For operational ice prediction, this suggests that forecast range in the winter is limited by the ability to predict the freezing of thinner ice. The next step in this work will be to examine the combined effects of dynamics and thermodynamics on ice predictability.

\section{ACKNOWLEDGEMENTS}

I should like to thank D. B. Rao, V.M. Haliburton, L. Breaker, W. Gemmill and G. Wohl for their assistance in preparing this paper.

\section{REFERENCES}

Bourke, R.H. and R. P. Garrett. 1987. Sea ice thickness distributions in the Arctic Ocean. Cold Reg. Sci. Technol., 13(3), 259-280.

Chapman, W.L. and J.E. Walsh. 1991. Long-range prediction of regional sea ice anomalies in the Arctic. Weather and Forecasting, 6(2), 271-288.
Coon, M.D., G.A. Maykut, R.S. Pritchard, D. A. Rothrock and A.S. Thorndike. 1974. Modeling the pack ice as an elastic-plastic material. AIDFEX Bull. 24, 1-105.

Grenfell, T.C. and G. A. Maykut. 1977. The optical properties of ice and snow in the Arctic Basin. J. Glaciol., 18(80), 445-463.

Hibler, W.D., III and J.E. Walsh. 1982. On modeling seasonal and interannual fluctuations of Arctic sea ice. F. Phys. Oceanogr., 12(12), $1514-1523$

Johnson, C. M., P. Lemke and T.P. Barnett. 1985. Linear prediction of sea ice anomalies. 7. Geophys. Res., 90(D3), 5665-5675.

Marsden, R.F., L. A. Mysak and R.A. Myers. 1991. Evidence for stability enhancement of sea ice in the Greenland and Labrador seas. 7. Geophys. Res., 96(C3), 4783-4789.

Maykut, G.A. 1986. The surface heat and mass balance. In Untersteiner, N., ed. The geophysics of sea ice. New York, Plenum Press, 395-463. (NATO ASI Series. Ser. B. Physics, 146.)

Maykut, G.A. and P.E. Church. 1973. Radiation climate of Barrow, Alaska, 1962-66. F. Appl. Meteorol., 12(4), 620-628.

Maykut, G.A. and N. Untersteiner. 1971. Some results from a timedependent thermodynamic model of sea ice. F. Geophys. Res., 76(6), 1550-1575.

Parkinson, C. L. and W. M. Washington. 1974. A large-scale numerical model of sea ice. 7. Geophys. Res., 84(C1), 311-337.

Semtner, A., Jr. 1976. A model for the thermodynamic growth of sea ice in numerical investigations of climate. F. Phys. Oceanogr., 6(3), 379-389.

Thorndike, A. S., D. A. Rothrock, G. A. Maykut and R. Colony. 1975 The thickness distribution of sea ice. F. Geophys. Res., 80(33), 4501-4513.

Wadhams, P., M. A. Lange and S.F. Ackley. 1987. The ice thickness distribution across the Atlantic sector of the Antarctic ocean in midwinter. F. Geophys. Res., 92(C13), 14,535-14,552.

Walsh, J.E. 1980. Empirical orthogonal functions and the statistical predictability of sea ice extent. In Pritchard, R. S., ed. Sea ice processes and models. Seattle and London, University of Washington Press, 373-384.

Walsh, J.E. and C.M. Johnson. 1979. Interannual variability and associated fluctuations in Arctic sea ice extent. 7. Geophys. Res., 84(C11), 6915-6928.

The accuracy of references in the text and in this list is the responsibility of the author, to whom queries should be addressed. 